\title{
Insect parasites in multicomponent systems and development of new bioinsecticides
}

\author{
Viktor Glupov ${ }^{1, *}$, Vyacheslav Martemyanov ${ }^{1}$, and Vadim Kryukov ${ }^{1}$ \\ ${ }^{1}$ Institute of Systematics and Ecology of Animals SB RAS, 630091 Novosibirsk, Russia
}

\begin{abstract}
Stable and dynamic interactions among plants, herbivorous insects, parasites and associated microbes are formed in natural habitats. The study of these interactions in multicomponent models is required to develop integrated methods for the management of insect pest populations. In this work, we summarize our studies on the influence of different factors, such as hygrothermal conditions, host development, host microbiota, plant quality, and concomitant infections, on interactions between insects and their parasites, such as fungi, bacteria, viruses and parasitoids. Some approaches for developing complex products for biocontrol are also discussed. For example, the use of natural compounds with immunosuppressive effects may enhance the efficacy of microbial agents toward pest insects.
\end{abstract}

\section{Introduction}

In natural ecosystems and agroecosystems, insects and their parasites are exposed to a broad range of factors, such as temperature, solar radiation, plant and microbial metabolites, as well as insecticides. Complicated interrelations in the host-parasite systems are therefore established. These systems exhibit intriguing models for ecological and immunological studies. The ecological properties and virulence of microorganisms are dependent on the species and strain. It is quite natural that these particular features should be considered for strains of bioinsecticide products [1]. Plants and insects have been coexisting for more than 400 million years; therefore, they form stable dynamic systems in which endosymbionts and parasites also participate [2-3]. Among the parasites involved in this system, we can find species of various taxonomic groups ranging from viruses, bacteria and fungi to protists and invertebrates (e.g., nematodes and parasitic insects). These organisms can form associations with both plants and insects, causing changes in various parts of the systems [4-5]. Moreover, in these systems, the role of certain components can change; for example, entomopathogenic microorganisms entering into association with plants will enhance plant growth and resistance to diseases. Therefore, to create new bioinsecticides and approaches for their use, it is necessary to study the multicomponent systems as a whole. However, we need to know the properties of certain components, that is, plants, insects and microorganisms, including how they can change under the influence of certain conditions.

\footnotetext{
*Corresponding author: skif@eco.nsc.ru
} 


\section{Pathogen virulence and ecological fitness}

It is well known that strains of one species or cryptic species of one genus may significantly differ in virulence, which is mediated by environmental adaptations. For example, cryptic species of the fungus Metarhizium have different hygrothermal preferences and may be associated with different habitats [6]. We have shown that the virulence of the cryptic species M. brunneum and M. robersii toward Colorado potato beetle (CPB) was mediated by hygrothermal conditions [7]. $M$. robersii was active against the CPB under both humid and arid regimes, although $M$. brunneum was less virulent under arid conditions than under humid conditions. Therefore, using $M$. robertsii will be more effective against CPB larvae in open ground under continental climate conditions. Similar effects were shown for natural isolates of Beauveria bassiana s.l. In particular, steppe isolates were more thermotolerant and most virulent toward wax moth and $\mathrm{CPB}$ under arid regimes as compared to forest and foresttundra isolates [8].

Population differences of viral entomopathogens in terms of virulence are partially determined by their genetic differences. In particular, the strains of Lymantria dispar multiple nucleopolyhedrovirus (LdMNPV, Baculoviridae) isolated in North America possess higher virulence than the Asian strain because of vef-1 gene deletion [9-10]. However, the phenotypic expression of these genetic differences does not depend on the host population [10]; conversely, it is ruled by the environmental conditions. In particular, sunlight easily decreases the potency of the American strain by UV even after 15 min of exposure, while the Asian strain possesses higher UV tolerance [11]. These features of highly potent strains should be considered for the producers of bioformulations for pest control.

\section{Physiological state of hosts}

The immuno-physiological state of insect hosts plays a crucial role in the development of pathogenesis. Host populations and ontogenetic stages differ significantly in their susceptibility to infections. For example, wax moths demonstrate different immune responses to fungal infection under an active state and under a facultative diapause [12]. Larval diapause induced by decreasing temperature was most favorable for the development of the fungus Cordyceps militaris due to a decrease in phenoloxidase activity and encapsulation rate. Additionally, while fought off in the active state of the host, the infection could still be activated in the diapause state. Interestingly, viral pathogenesis does not depend on the phenoloxidase activity that was shown on $L$. dispar larvae using several lines of evidence [13]. The larvae of CPB demonstrated strong differences in susceptibility to the fungus Metarhizium during the intermolt period of the last instar due to the changes in integument thickness and epicuticular hydrocarbon contents (which determine the level of conidial adhesion) as well as changes in cellular immunity [14]. The solitaria phase of migratory locust was more resistant to fungi (Metarhizium and Beauveria) than to gregaria [15]. In experiments with another pest species (L. dispar), we did not demonstrate the effect of gregariously reared larvae on susceptibility to an entomopathogenic virus as compared to the larvae reared solitarily [16]. 


\section{Interactions between parasites and host microbial communities}

Insect symbiotic bacteria may inhibit or promote the development of parasitoids and pathogenic microorganisms [17-18]. Recent studies have shown intriguing interactions between gut microbiota of the host and its fungal pathogens [18]. In particular, the penetration of the fungus through integuments may lead to an increase in the gut bacterial load that promotes fungal infection [19]. Inhibition of gut bacteria with antibiotics enhances insect survival after topical application of fungi [20]; however, the opposite effect is usually observed after oral administration of the fungi [e.g., 21]. We showed that the envenomation of wax moth larvae by the parasitoid Habrobracon hebetor as well as a combination of envenomation and B. bassiana infection led to a shift in the balance among Enterococcus, Enterobacter and Serratia in the wax moth midgut [22]. Envenomation causes uncontrolled proliferation of gut bacteria; however, the strong activation of antimicrobial peptides in the midgut was observed. We suggest that the activation of wax moth gut immunity prevents the bacterial decomposition of envenomated larvae, thus permitting the development of parasitoids and fungi. Moreover, the oral administration of predominant bacteria (Enterococcus, Enterobacter and Serratia) to the wax moth larvae synergistically increased susceptibility to the fungi [22]. Thus, the changes in the midgut bacterial community may promote death of larvae induced by the fungi. Interestingly, the combined treatment of the larvae with the aforementioned symbiotic bacteria and Bacillus thuringiensis led to antagonistic effects on mortality (O. Polenogova, unpublished). In other experiments, we demonstrated that the diversity of bacteria in the L. dispar midgut was decreased by the consumption of low-quality leaves and was associated with a decrease in the susceptibility of the insects to the entomopathogenic bacterium B. thuringiensis [23].

\section{Interactions among insects, parasites and plants}

It is known that the host plant quality may affect both the primary and the higher level (secondary) consumers [24-25]. However, the expression of this effect strongly depends on many factors, including the species involved and the weather conditions. For example, defoliation of oak Quercus rubra by L. dispar may induce an increase in the phenolic concentration in leaves that will inhibit both the life history traits of herbivores and their susceptibility to LdMNPV [26]. Alternatively, when the host plant is silver birch Betula pendula, the induction of phenolics (and possibly another phytochemicals) synthesis leads to a negative effect on herbivores [27-29] but has no effect on the interaction between L. dispar and LdMNPV [28] or the entomopathogenic bacteria Bacillus thuringiensis [30]. One chemical defense mechanism triggered by defoliation, which was shown for $B$. pendula, is the trade-off between glycosides and aglycons of flavonoids [27]. Synthesis of monoterpens is also induced by tree defoliation, especially at the moment of defoliation, which may be the chemical signal attracting parasitoids to the location of defoliators [27, 31]. The interactions between host plants, herbivores and pathogens/parasites significantly depend on the weather conditions, which may i) directly modify the traits of each participant of the food chain and ii) indirectly synchronize or desynchronize the phenological development of plants and herbivores, which is related to the dynamics of plant phytochemistry during a season. The effect of weather-induced asynchrony between the phenological development of plants and insects on insect survival via the dynamics of plant chemicals was demonstrated approximately 50 years ago [32] and provided the start of a new direction in ecology, i.e., chemical ecology. However, we recently showed that a mismatch in synchrony may spread further though the food chain, effecting the interaction between insects and entomopathogens [23, 33-34]. Moreover, this effect will depend on the type of pathogen involved in this interaction. For example, viruses have the advantage when insects appear asynchronously 
(because of cold weather) with the host plants [33], while this is disadvantageous for bacteria [33]. The host plant-mediated modification of an insect's innate immunity status is one of the mechanisms determining the outcome of insect-pathogen interactions [23].

\section{Multicomponent approaches in biological control}

The study of interactions in multicomponent systems allows the development of new products for biocontrol. For example, the use of natural compounds with immunosuppressive effects may enhance the efficacy of microbial agents toward insect pests. We studied the effects of different microbial and plant metabolites (e.g., Streptomyces toxins, usnic acid derivatives, and Cordyceps extracts) as well as mixed infections on the defense systems and development of pathogeneses in different insects such as wax moth, CPB and four-eyed fir bark beetle Polygraphus proximus, and mosquito Aedes aegypti [35-40]. The synergy between pathogenic fungi (Metarhizium, Beauveria) and bacteria (B. thuringiensis) or between these fungi and the aforementioned metabolites was shown. We found that the synergy is caused by changes in cellular and humoral immunity responses, gut microbiota, morphological and biochemical properties of integuments that stipulate fungal adhesion, penetration and colonization. We also suggest that the disturbance in larval development caused by these metabolites and bacteria has a great impact on immunity, integument properties and susceptibility to fungi [14]. The investigated combinations provide a stable synergy in laboratory and field experiments. These combinations may be promising for the development of efficient products to manage pest insects.

The study was supported by the Russian Science Foundation (project № 19-14-00138).

\section{References}

1. L.A. Lacey, D. Grzywacz, D.I. Shapiro-Ilan, R. Frutos, M. Brownbridge, M.S. Goettel, J. Invertebr. Pathol. 132, 1-41 (2015) http://doi/org/10.1016/j.jip.2015.07.009

2. A. Sugio, G. Dubreuil, D. Giron, J.-C. Simon. J. Experimen. Bot. 66, 467-478 (2015) http://doi/org/10.1093/jxb/eru435

3. J. Lazebnik, E. Frago, M. Dicke, J.J.A. van Loon. J. Chem. Ecol. 40, 730-741 (2014) http://doi/org/10.1007/s10886-014-0480-7

4. K.F. Raffa, P. Bonello, J.L. Orrock, New Phytologist (to be published) http://doi/org/10.1111/nph.16181

5. F.P. Franco, D.S. Moura, J.M. Vivanco, M.C. Curr. Opin. Microbiol. 37, 54-60 (2017)

6. M.J. Bidochka, A.M. Kamp, T.M. Lavender, J.Dekoning, J.N.A. De Croos, Appl. Environ. Microbiol. 67, 1335-1342 (2001)

7. V. Kryukov, O. Yaroslavtseva, M. Tyurin, Y. Akhanaev, E. Elisaphenko, T.-C. Wen, O. Tomilova, Y. Tokarev, V. Glupov, J. Invertebr. Pathol. 149, 1-7 (2017) http://doi/org/10.1016/j.jip.2017.07.001

8. V.Yu. Kryukov, O.N. Yaroslavtseva, E.A. Elisaphenko, P.V. Mitkovets, G.R. Lednev, B.A. Duisembekov, S.M. Zakian, V.V. Glupov, Microbiology. 81. 453-459 (2012) http://doi/org/10.1134/S002626171204011X

9. V.V. Martemyanov, M.R. Kabilov, A.E. Tupikin, O.A. Baturina, I.A. Belousova, J.D. Podgwaite, A.V. Ilynykh, V.V. Vlassov, Dokl. Biochem. Biophys. 465, 351-353 (2015) http://doi/org/10.1134/S1607672915060022

10. V.V. Martemyanov, J.D. Podgwaite, I.A. Belousova, S.V. Pavlushin, J.M. Slavicek, O.A. Baturina, M.R. Kabilov, A.V. Ilyinykh, J. Invertebr. Pathol. 146, 41-46 (2017) http://doi/org/10.1016/j.jip.2017.04.004 
11. Y.B. Akhanaev, I.A. Belousova, N.I. Ershov, M. Nakai, V.V. Martemyanov, V.V. Glupov, PLoS One. 12, e0189992 (2017) http://doi/org/10.1371/journal.pone.0189992

12. V.Yu. Kryukov, O.G. Tomilova, O.N. Yaroslavtseva, T.-C. Wen, N.A. Kryukova, O.V. Polenogova, Y.S. Tokarev, V.V. Glupov, Fungal Ecology 35, 98-107 (2018) http://doi/org/10.1016/j.funeco.2018.07.003

13. N.S. Kasianov, I.A. Belousova, S.V. Pavlushin, I.M. Dubovskiy, J.D. Podgwaite, V.V. Martemyanov, S.A. Bakhvalov, PLoS One 12, e0183940 (2017). http://doi/org/10.1371/journal.pone.0183940

14. O.G. Tomilova, O.N. Yaroslavtseva, M.D. Ganina, M.V. Tyurin, E.I. Chernyak, I.V. Senderskiy, Y.A. Noskov, O.V. Polenogova, Y.B. Akhanaev, V.Y. Kryukov, V.V. Glupov, J. Insect Physiol. $116,106-117$ (2019) http://doi/org/10.1016/j.jinsphys.2019.05.003.

15. V.Yu Kryukov, G.R Lednev, I.M. Dubovskiy, V.V. Serebrov, M.V., Levchenko, V.P. Khodyrev, A.O. Sagitov, V.V. Glupov, Euroasian Entomol. J. 6, 195-204 (2007)

16. S.V. Pavlushin, I.A. Belousova, E.A. Chertkova, N.A. Kryukova, V.V. Glupov, V.V. Martemyanov, Eur. J. Entomol. 116, 85-91 (2019)

17. M. Kaltenpoth, T. Engl, Funct. Ecol. 28, 315-327 (2013) http://doi/org/10.1111/13652435.12089

18. D.G. Boucias, Y. Zhou, S. Huang, N.O. Keyhani, Appl. Microbiol. Biotechnol. 102, 5873-5888 (2018) http://doi/org/10.1007/s00253-018-9089-z.

19. G. Wei, Y. Lai, G. Wang, H. Chen, F. Li, S. Wang, PNAS 114, 5994-5999 (2017) http://doi/org/10.1073/pnas. 1703546114.

20. L. Xu, J. Deng, F. Zhou, C. Cheng, L. Zhang, J. Zhang, M. Lu, J. Pest. Sci. 92, 343-351 (2019) http://doi/org/10.1007/s10340-018-0999-4

21. F. Zhang, X.X. Sun, X.C. Zhang, S. Zhang, J. Lu, Y.M. Xia, Y.H. Huang, X.J Wang, Pest Manag. Sci. 74, 438-447 (2018) http://doi/org/10.1002/ps.4726

22. O.V. Polenogova, M.R. Kabilov, M.V. Tyurin, U.N. Rotskaya, A.V. Krivopalov, V.V. Morozova, K. Mozhaitseva, N.A. Kryukova, T. Alikina, V.Yu. Kryukov, V.V. Glupov, Sci. Rep. 9, 4012 (2019) http://doi/org/10.1038/s41598-019-40301-6

23. V.V. Martemyanov, I.A. Belousova, S.V. Pavlushin, I.M. Dubovskiy, N.I. Ershov, T.Y. Alikina, M.R. Kabilov, V.V. Glupov, Ecol. Evol. 6, 7298-7310 (2016) http://doi/org/10.1002/ece3.2460

24. J.S. Cory, K. Hoover, Trends Ecol. Evol. 21, 278-286 (2006) http://doi/org/10.1016/j.tree.2006.02.005

25. T.C.J. Turlings, M. Erb, Annu. Rev. Entomol. 63, 433-452 (2018) http://doi/org/10.1146/annurev-ento-020117-043507

26. M.D. Hunter, J.C. Schultz, Oecologia. 94, 195-203 (1993) http://doi/org/10.1007/BF00341317

27. V.V. Martemyanov, I.M. Dubovskiy, I.A. Belousova, S.V. Pavlushin, D.V. Domrachev, M.J. Rantala, J-P, Salminen, S.A. Bakhvalov, V.V. Glupov, Arthropod-Plant Interact. 6, 507-518 (2012). http://doi/org/10.1007/s11829-012-9202-7

28. V.V. Martemyanov, I.M. Dubovskiy, M.J. Rantala, J.P. Salminen, I.A. Belousova, S.V. Pavlushin, S.A. Bakhvalov, V.V. Glupov, J. Chem. Ecol. 38, 295-305 (2012) http://doi/org/10.1007/s10886-012-0090-1

29. V.V. Martemyanov, S.V. Pavlushin, I.M. Dubovskiy, I.A. Belousova, Y.V. Yushkova, S.V. Morosov, E.I. Chernyak, V.V. Glupov, PLoS One. 10, e0121917 (2015) http://doi/org/10.1371/journal.pone.0121917

30. I.A. Belousova, V.V. Martemyanov, V.V. Glupov, Russ. J. Ecol. 48, 116-121 (2017) http://doi/org/10.1134/S1067413617020047 
31. V.V. Martemyanov, D.V. Domrachev, S.V. Pavlushin, I.A. Belousova, S.A. Bakhvalov, A.V. Tkachev, V.V. Glupov, Dokl. Biol. Sci. 435, 407-410 (2010) http://doi/org/10.1134/S0012496610060104

32. P.P. Feeny, Ecology 51, 565-581 (1970)

33. V.V. Martemyanov, S.V. Pavlushin, I.M. Dubovskiy, Y.V. Yushkova, S.V. Morosov, E.I. Chernyak, V.M Efimov, T. Ruuhola, V.V. Glupov, PLoS One. 10, e0130988 (2015) http://doi/org/10.1371/journal.pone.0130988

34. E.I. Chernyak, Yu.V. Yushkova, S.V. Pavlushin, S.O. Nikolenko, V.V. Martemyanov, S.V. Morozov, Chem. Nat. Compd. 52, 193-198 (2016) http://doi/org/10.1007/s10600016-1592-9

35. O.G. Tomilova, V.Yu. Kryukov, B.A. Duisembekov, O.N. Yaroslavtseva, M.V. Tyurin, N.A. Kryukova, V. Skorokhod, I.M. Dubovskiy, V.V. Glupov, J. Invertebr. Pathol. 140. 8-15 (2016) http://doi/org/10.1016/j.jip.2016.08.008

36. O.N. Yaroslavtseva, I.M. Dubovskiy, V.P. Khodyrev, B.A. Duisembekov, V.Yu. Kryukov, V.V. Glupov, J. Insect. Physiol. 96, 14-20 (2017) http://doi/org/10.1016/j.jinsphys.2016.10.004

37. V.Yu. Kryukov, O.N. Yaroslavtseva, I.M. Dubovskiy, M.V. Tyurin, N.A. Kryukova, V.V. Glupov, Biol. Bull. 41, 276-283 (2014) http://doi/org/10.1134/S1062359014020046

38. V.Yu. Krukov, O.G. Tomilova, O.A. Luzina, O.N. Yaroslavtseva, Yu.B. Akhanaev, M.V. Tyurin, B.A. Duisembekov, N.F. Salakhutdinov, V.V. Glupov, Pest Manag. Sci. 74, 598606 (2018) DOI:10.1002/ps.4741

39. I.A. Kerchev, N.A. Kryukova, V.Yu. Kryukov, V.V. Glupov, ISJ 14, 324-329 (2017)

40. Y.A. Noskov, O.V. Polenogova, O.N. Yaroslavtseva, O.E. Belevich, Y.A. Yurchenko, E.A. Chertkova, N.A. Kryukova, V.Yu Kryukov, V.V. Glupov, PeerJ 7, e7931 (2019) DOI. 10.7717 peerj.7931 